\title{
Cohydrothermal carbonization of waste polyvinyl chloride and wood chip for dechlorination
}

\author{
K Kusakabe ${ }^{1, *}$, T Steven ${ }^{2}$, JY Ong ${ }^{3}$, Y Uemura ${ }^{3}$ and K Ikenaga ${ }^{1}$ \\ ${ }^{1}$ Department of Nanoscience, Sojo University, 4-22-1 Ikeda, Nishi-ku, Kumamoto 860-0082, Japan \\ ${ }^{2}$ Department of Applied Science, Universiti Teknologi of PETRONAS, 32610 Seri Iskandar, Perak Darul Ridzuan, Malaysia \\ ${ }^{3}$ Department of Chemical Engineering, Universiti Teknologi of PETRONAS, 32610 Seri Iskandar, Perak Darul Ridzuan, Malaysia
}

\begin{abstract}
The co-hydrothermal carbonization (Co-HTC) of polyvinyl chloride (PVC) film and wood chip (WC) was conducted at $200-260^{\circ} \mathrm{C}$ in an autoclave filled in air or nitrogen for the chemical recycling of wastes with dechlorination of PVC. Effects of the Co-HTC temperature and the oxidation reaction during the Co-HTC on the decomposition behaviors were investigated. The percentage decomposition in nitrogen atmosphere increased with increasing the reaction temperature and reached $76.1 \%$ at $260^{\circ} \mathrm{C}$. The percentage decompositions in nitrogen were several percent higher than those in air. The synergistic effect of PVC and WC for the decomposition was observed at $220^{\circ} \mathrm{C}$ in $\mathrm{N}_{2}$. When the Co-HTC was performed in air, decomposition was suppressed, indicating the increase in hydrochar yield. The dechlorination yield was determined from the $\mathrm{Cl}$ content in the recovered PVC after the Co-HTC reaction. Under nitrogen atmosphere conditions, the dechlorination yield increased slightly with increasing the temperature. At a carbonization temperature of $260^{\circ} \mathrm{C}$, the dechlorination yield of $\mathrm{PVC}$ was about $40 \%$.
\end{abstract}

\section{Introduction}

The treatment method of waste polyvinyl chloride (PVC) resins discarded from industrial, agricultural, and architectural fields has been established through material recycling in Japan. However, general waste plastics mixed with PVC products have been subjected to the thermal decomposition [1-3] and the landfill treatment. The thermal recycling of PVC is particularly difficult to process because it produces harmful $\mathrm{HCl}$ gas and organic halides during pyrolysis. Dechlorination ratio reaches $90 \%$ in the advanced PVC pyrolysis method above 600K. [4] However, the yield of solid residue is $10-20 \%$ and the loss of hydrocarbon is large. Therefore, the research on efficient dechlorination methods is required.

Hydrothermal carbonization (HTC) technology has been considered as one of the most promising ways of recycling solid waste to produce hydrochar. [5] In HTC treatment, solid waste such as waste plastics and biomass are heat-treated in subcritical water. The advantage of HTC is its relatively low process temperature, no need to dry the feedstock, the homogenized composition of the product, and a high relative carbon content in the product. Previous studies have shown that $50-90 \%$ of carbon contained in the feedstock remains in the hydrochar which was produced by HTC. Alkaline compounds are added to the HTC of PVC to enhance the reaction, but environmental problems remain in term of waste treatment. Poerschmann et al., [6] carried out the HTC of PVC at $180-260^{\circ} \mathrm{C}$. Dechlorination increased with increasing reaction temperature and the removal chlorine was almost quantitative above $235^{\circ} \mathrm{C}$.

Co-hydrothermal carbonization (Co-HTC) can promote the synergistic interaction between the two feedstocks by the simultaneous HTC treatment. Shen et al. [7] reported that the Co-HTC of PVC-containing medical waste and three lignocellulosic components (lignin, cellulose and hemicellulose). The dechlorination performance of lignocellulosic components is given as the following order: lignin $>$ cellulose $>$ hemicellulose. During the Co-HTC, a large amount of free $\mathrm{OH}$ group in biomass converted from organic chlorine in PVC to the inorganic chlorine. Yao and $\mathrm{Ma}[8]$ treated PVC and bamboo by Co-HTC at 200,230 and $260^{\circ} \mathrm{C}$. The inorganic-chlorine was removed from the hydrochar in the term of $\mathrm{HCl}$. The bamboo could accelerate the HTC dichlorination of $\mathrm{PVC}$ at $200^{\circ} \mathrm{C}$ because it strengthened the substitution of $\mathrm{Cl}$ with $\mathrm{OH}$. While at $230^{\circ} \mathrm{C}$ and $260^{\circ} \mathrm{C}$, the existence of bamboo hidered the dichlorination of PVC in HTC. Huang et al. [9] evaluated the dechlorination efficiency and the inorganics removal efficiency for clean biocoke production through the Co-HTC of PVC and pine sawdust. The most important factor for the dichlorination efficiency was the hydrothermal temperature, followed by residence time and particle size of the sawdust. The dichlorination efficiency could reach $64 \%$ by the Co-HTC at a temperature of $260^{\circ} \mathrm{C}$ for $120 \mathrm{~min}$. The addition of PVC and the temperature increase are not conductive to the formation of porous hydrochar. However, these research works have been conducted on pure PVC or powder. To realize the waste PVC treatment process, Co-HTC of biomass and the

\footnotetext{
* Corresponding author: kusakabe@nano.sojo-u.ac.jp
} 
commercial PVC resin containing the plasticizers or other additives have to be investigated. In addition, it is necessary to investigate the effect of the oxidation reaction during the $\mathrm{Co}-\mathrm{HTC}$.

In this work, Co-HTC of WC and commercial PVC resin film was performed in an autoclave at 200, 220, 240 and $260^{\circ} \mathrm{C}$ for 120 minutes. Effects of reaction temperature and oxygen atmosphere on the behaviours of the decomposition and the dechlorination were investigated.

\section{Materials and methods}

\subsection{Materials}

Wood chip (WC) of Juglans mandshurica var. sachalinensis for smoked uses was purchased from Shin-fuji Burner Co. Ltd., Japan and used as representative of lignocellulosic biomass. The WC was milled into small pieces and dried at $105^{\circ} \mathrm{C}$ in an oven for 2 hours. A commercially available PVC resin film with the thickness of $0.1 \mathrm{~mm}$ was cut into small pieces of several millimetres in size for use.

\subsection{Co-hydrothermal carbonization process (Co-HTC)}

The Co-HTC process was conducted using a $25 \mathrm{ml}$ autoclave reactor (San-ai Kagaku Co. Ltd., Japan). Figure 1 shows the schematic diagram of Co-HTC of WC and PVC. In each experiment, WC (0.2 g), PVC $(0.2 \mathrm{~g})$ and distilled water $(15 \mathrm{ml})$ were loaded into a decomposition container of the reactor. To investigate the effect of oxygen on Co-HTC process, the autoclave was shielded in a glove box filled with nitrogen or air. After heating the electric furnace to the desired temperature $\left(200,220,240\right.$ and $\left.260^{\circ} \mathrm{C}\right)$, the autoclave was placed in the furnace and heated for designed reaction time (120 min.). Separation of the hydrochar and the liquid filtrate was conducted by vacuum filtration. The hydrochar samples were dried in a vacuum oven at $105^{\circ} \mathrm{C}$ for 1 day to remove moisture.

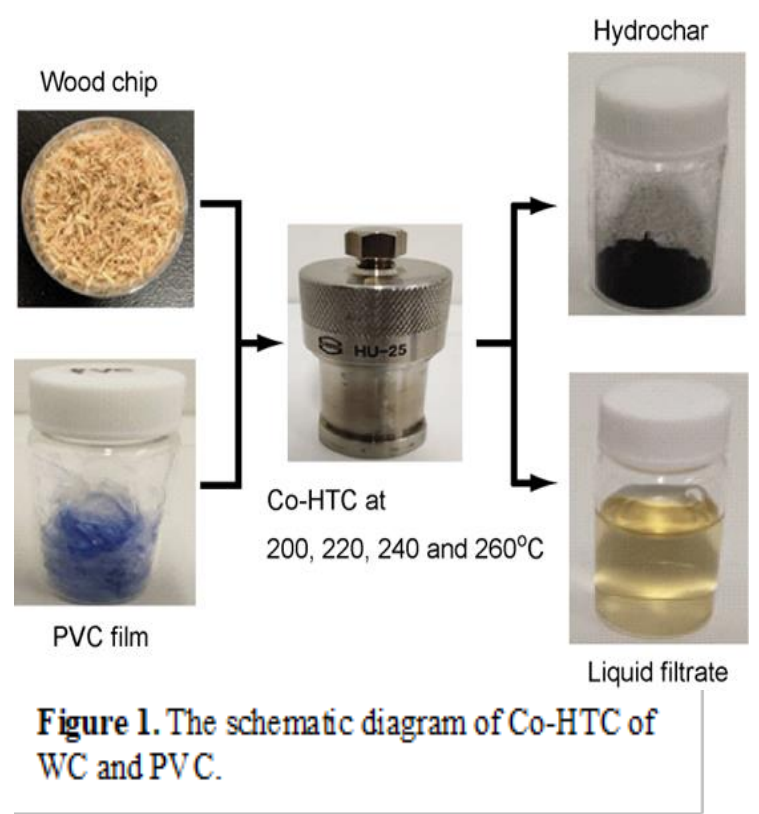

\subsection{Characterization}

The surface morphologies of the raw wood chip and the hydrochar samples were observed with a scanning electron microscope (SEM VE-9800, Keyence Japan). The thermal decomposition behavior of the biochar was evaluated via the thermogravimetric analysis with a TG/DTA (Hitachi A7220, Japan). The hydrochar samples $(20 \mathrm{mg})$ were heated from $30^{\circ} \mathrm{C}$ to $600^{\circ} \mathrm{C}$ at a linear heating rate of $10^{\circ} \mathrm{C} / \mathrm{min}$ under an argon flow of $100 \mathrm{ml} / \mathrm{min}$.

Percentage decomposition was calculated from the following equation.

Percentage decomposition $=\left(1-\frac{\text { mass of hydrochar }}{\text { mass of feedstock }}\right) \times 100 \%($ 1)

When the hydrochar yield is defined as the ratio of mass of hydrochar to mass of feedstock, hydrochar yield is equivalent to the value of $(1-$ percent decomposition/100).

The solid carbonized PVC residue was easily separated from the hydrochar. Therefore, $\mathrm{Cl}$ content in the PVC residue was measured by the combustion method. 50 $\mathrm{mg}$ of the PVC residue which was wrapped with a filter paper, was completely oxidized in a closed flask with a sodium carbonate solution under a pure oxygen atmosphere. The $\mathrm{Cl}$ concentration in the sodium carbonate solution was determined via an ion chromatography (Dionex Integrion HPIC system, Thermo Fisher Scientific, USA). The dechlorination yield of PVC was calculated via the following equation.

Dechlorination yield of PVC $=\left(1-\frac{\text { Clcontent incarbonized PVC }}{\text { Cl contentin initial PVC }}\right) \times 100 \%$ (2)

\footnotetext{
*Corresponding author: kusakabe@nano.sojo-u.ac.jp
} 


\section{Results and Discussion}

Figure 2 shows the surface morphologies of raw WC and hydrochar. Figure $2 \mathrm{a}$ reveals the elongated fibrous shapes of the unreacted WC with the intact surface before Co-HTC process. The smooth surface becomes rough after Co-HTC process. As shown in Figure $2 b$, the fibrous shape remained at $220^{\circ} \mathrm{C}$ and the disruption of the cell wall was small. As the temperature was raised to 240 and $260^{\circ} \mathrm{C}$ (Figure $2 \mathrm{c}$ and $2 \mathrm{~d}$ ), the development of pore structure become remarkable due to the evolution of $\mathrm{CO}_{2}$ and $\mathrm{H}_{2} \mathrm{O}$ during the carbonization..At $260^{\circ} \mathrm{C}$, the surface morphology of hydrochar obtained in air was almost the same as that in nitrogen.
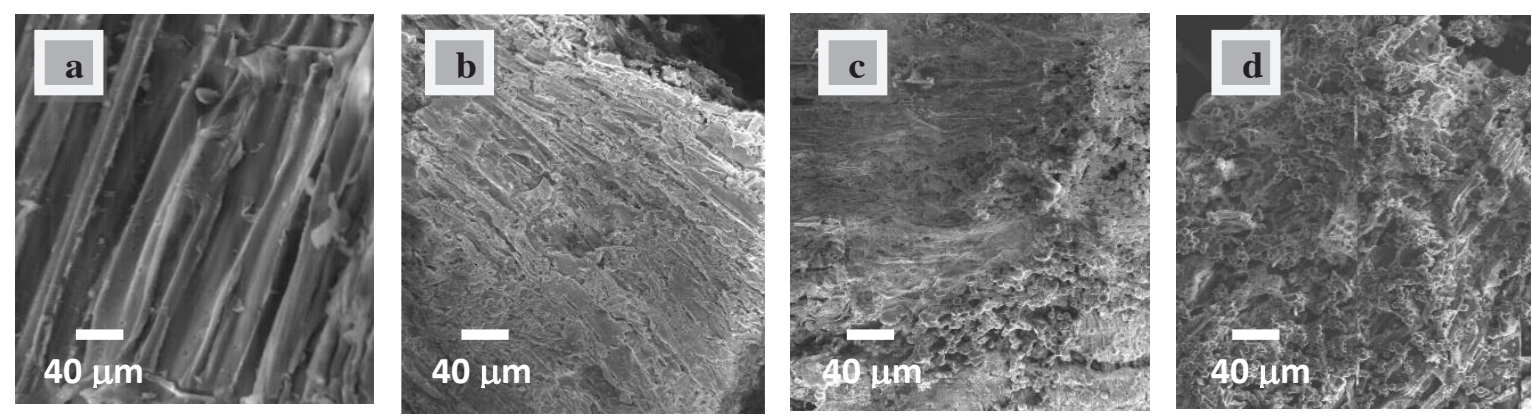

Figure 2. SEM images of (a) woodchip,(b) PVC/WC hydrochar at $220^{\circ} \mathrm{C}$,

(c) $\mathrm{PVC} / \mathrm{WC}$ at $240^{\circ} \mathrm{C}$,(d) $\mathrm{PVC} / \mathrm{WC}$ at $260^{\circ} \mathrm{C}: \mathrm{Co}-\mathrm{HTC}$ in $\mathrm{N}_{2}$.

HTC of WC or PVC was performed under the same conditions as Co-HTC of WC and PVC in this study. Figure 3 shows the effect of the temperature on the percentage decomposition in $\mathrm{N}_{2}$ atmosphere. HTC of WC indicated the highest percentage decomposition. The percentage decomposition of PVC hardly proceeds at $200^{\circ} \mathrm{C}$, and it was only $31.4 \%$ at $220^{\circ} \mathrm{C}$. However, by performing Co-HTC of PVC and $\mathrm{WC}$, the percentage decomposition of PVC/WC mixture was close to that of WC. A synergistic effect on the decomposition was observed with the combination of PVC and WC at 200$220^{\circ} \mathrm{C}$. Yao and $\mathrm{Ma}[8]$ reported that the Co-HTC of $\mathrm{PVC}$ and bamboo promoted decomposition at $200^{\circ} \mathrm{C}$, as in the present study, but conversely suppressed the decomposition at $230^{\circ} \mathrm{C}$ and $260^{\circ} \mathrm{C}$. As shown in Fig.2, Co-HTC of PVC and WC show no suppression effect at $240^{\circ} \mathrm{C}$ and $260{ }^{\circ} \mathrm{C}$. These behaviours are thought to be due to the difference in the content of hemicellulose, cellulose and lignin between bamboo and WC.

The percentage decompositions in air and $\mathrm{N}_{2}$ were compared to clear the effect of oxidation on Co-HTC of PVC and WC. As shown in Figure 4, oxidation by oxygen in air accelerated the decomposition during the HTC of PVC. However, for HTC of WC and Co-HTC of $\mathrm{PVC}$ and $\mathrm{WC}$, high percentage decomposition was obtained in $\mathrm{N}_{2}$ atmosphere. Table 1 summarizes the results of the percent decomposition. In the Co-HTC of PVC and WC, the percentage decompositions in $\mathrm{N}_{2}$ were several percent higher than those in air. This means that oxygen remains as oxygen-containing functional groups due to WC surface oxidation during the Co-HTC in air. Assuming that oxygen remains as an oxygen-containing functional group in the solid residue after carbonization, it is considered that the weight of the solid residue increases in air and the percentage decomposition apparently decreases. The total amount of gaseous oxygen in the autoclave was calculated to be $2.56 \mathrm{mg}$, which is sufficient enough to reduce the percent decomposition by several percent.

\footnotetext{
* Corresponding author: kusakabe@nano.sojo-u.ac.jp
}

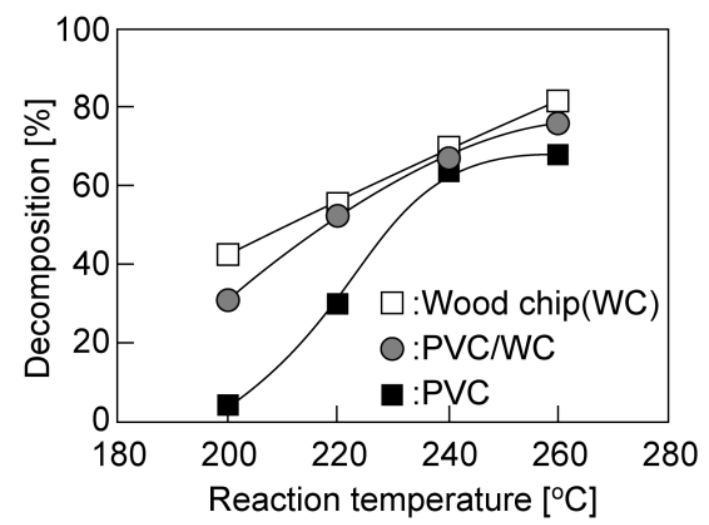

Figure 3. Effect of hydrothermal temperature on the percent decomposition.

In Table 1, the percent decomposition for HTC of WC and $\mathrm{PVC}$ are expressed as $\mathrm{P}_{\mathrm{WC}}$ and $\mathrm{P}_{\mathrm{PV}}$, respectively, and the percentage decomposition rates of the Co-HTC are expressed as $\mathrm{P}_{\mathrm{PVC} / \mathrm{WC}}$. When the synergistic effect due to Co-HTC is evaluated by calculating the value of $\mathrm{P}_{\mathrm{PVC} / \mathrm{WC}} /\left[(1 / 2)\left(\mathrm{P}_{\mathrm{WC}}+\mathrm{P}_{\mathrm{PV}}\right)\right]$, the synergistic effect on decomposition is observed only at $220^{\circ} \mathrm{C}$ under nitrogen atmosphere. On the other hand, in air, the value of the synergistic effect became less than one at any temperature due to the increase in oxygen-containing functional groups. Conversely, hydrochar yield became high in air. 


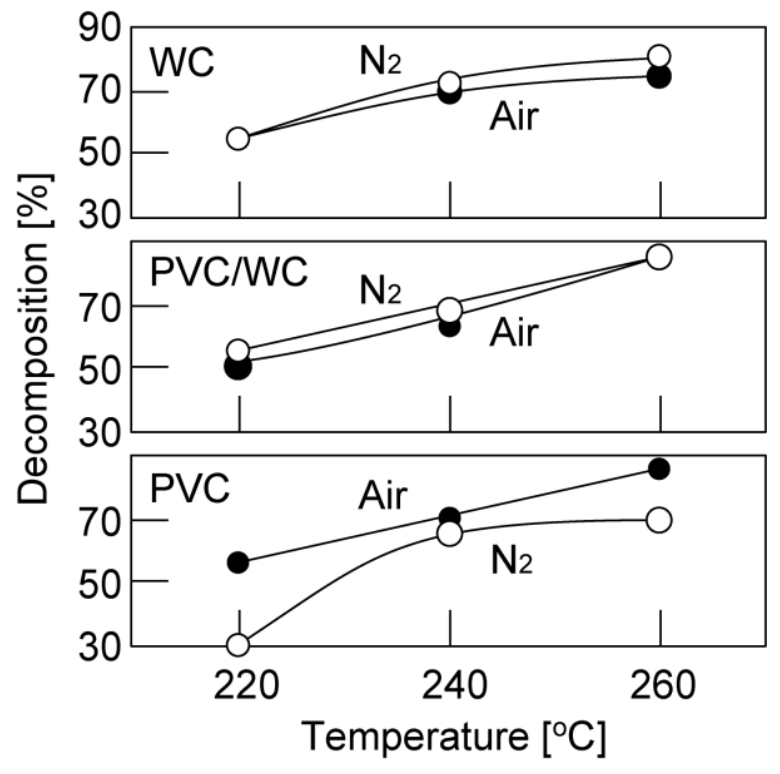

Figure 4. Effect of oxidation during HTC on the percent decomposition.

Table 1. Synergy effect of Co-HTC.

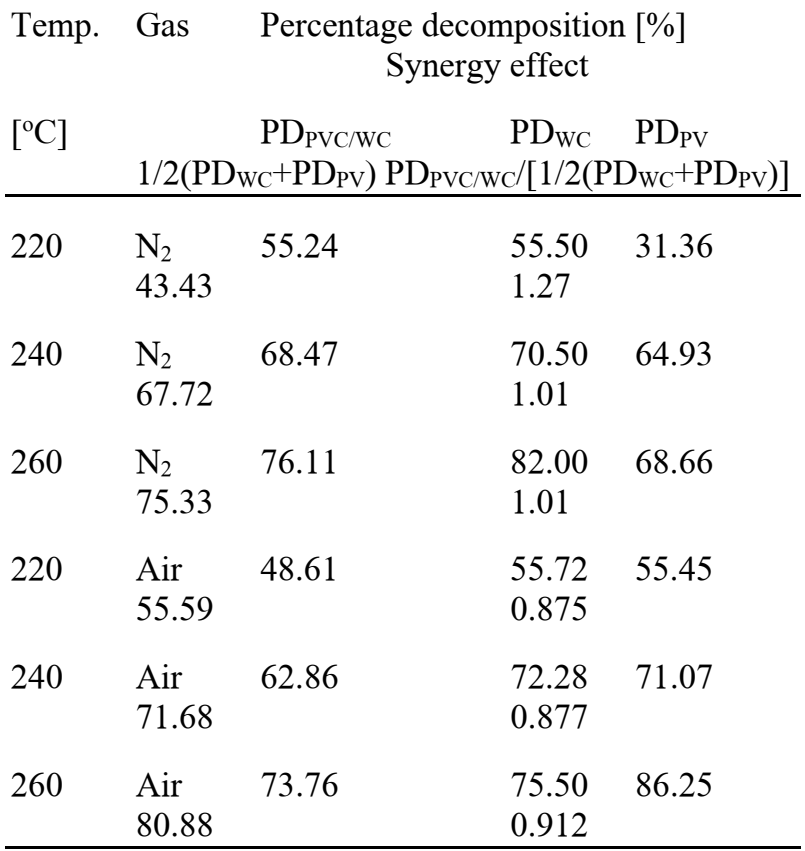

Figure 5 reveals that the dechlorination yields for the recovered PVC sample in $\mathrm{N}_{2}$ are higher than those in air. Under nitrogen atmosphere conditions, the dechlorination yield increased slightly with temperature. Even at a carbonization temperature of $260^{\circ} \mathrm{C}$, the dechlorination yield was about $40 \%$. Dechlorination proceeded in two ways: elimination and substitution reaction. For the elimination reaction, chlorine in the polymer chain was converted to hydrogen chloride, generating a double bond in PVC [10]. As the elimination proceeds, some compounds with polyene structure are formed, and thereafter, aromatic compounds are formed by a cyclization reaction. For the substitution reaction, $\mathrm{C}-\mathrm{OH}$ functional groups are formed in PVC by a substitution reaction between chlorine in the polymer chain and a hydroxyl group in biomass. The HTC of PVC usually promotes the dechlorination under basic conditions [11], which suggests that oxygen-containing functional groups in biomass would significantly affect the dechlorination reaction.

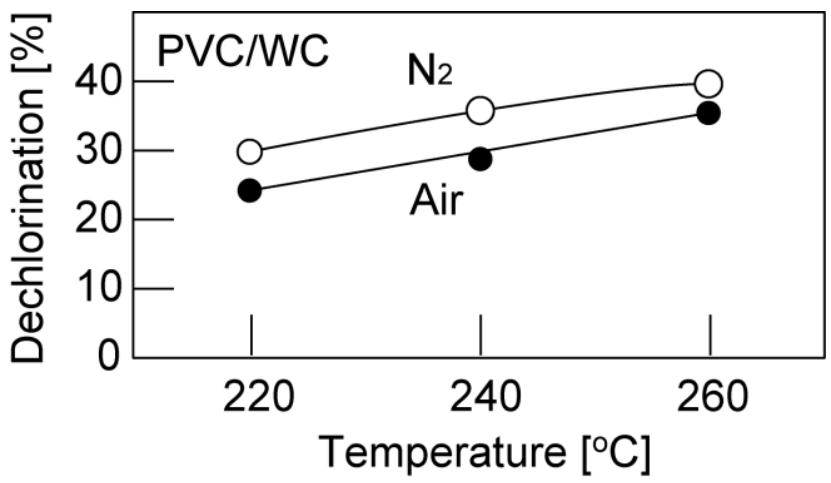

Figure 5. Dechlorination yield for the Co-HTC of PVC and WC.

Figure 6 shows differential thermo-gravimetry (DTG) of feedstock WC and carbon residues after HTC of WC at $220-260^{\circ} \mathrm{C}$. The shoulder peak observed in the TG temperature range of $200^{\circ} \mathrm{C}$ to $220^{\circ} \mathrm{C}$ indicates the thermal decomposition of hemicelluloses containing in WC [11]. The TG peak at $340^{\circ} \mathrm{C}$ corresponds to the thermal decomposition of cellulose. The broad peak observed above $380^{\circ} \mathrm{C}$ is generally considered to be the thermal decomposition of lignin and can be hardly observed in this study, indicating that lignin content in the feedstock WC is low. When the feedstock WC was hydrothermally carbonized at $220^{\circ} \mathrm{C}$, the hemicellulose component was preferentially completely decomposed. Increasing the $\mathrm{HTC}$ temperature up to $260^{\circ} \mathrm{C}$, cellulose component was gradually decomposed. In addition, the broad peak above $380^{\circ} \mathrm{C}$ became large, indicating the formation of the products by cleavage of the cellulose main chain. The similar results were obtained from the research on the TG measurements of the torrefied wood chip [12].

The DTG of the solid residue after Co-HTC of PVC and WC together with PVC are shown in Figure 7. PVC has a large peak at around $280^{\circ} \mathrm{C}$ due to the removal of hydrogen chloride and volatilization of lower hydrocarbon aromatic compounds, formed by the dechlorination reaction. A second peak at $450^{\circ} \mathrm{C}$ was caused by the volatilization of heavier aromatic compounds [13].

\footnotetext{
*Corresponding author: kusakabe@nano.sojo-u.ac.jp
} 


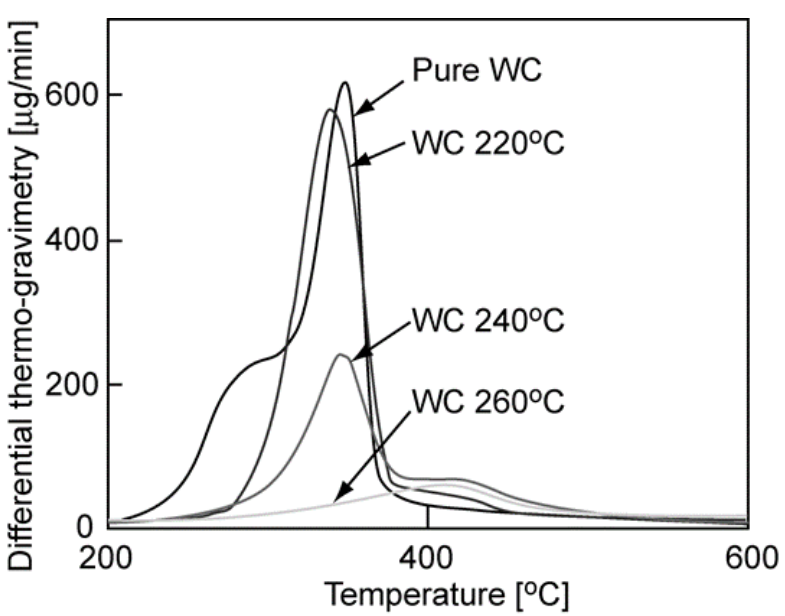

Figure 6. DTG curves obtained from the feedstock WC and the hydrochar after HTC of WC

The DTG of the solid residue after the Co-HTC reaction at $220{ }^{\circ} \mathrm{C}$ showed the behaviour similar to that of untreated PVC. For the Co-HTC of PVC and WC, the peak at $340^{\circ} \mathrm{C}$ in Figure 6 due to the decomposition of cellulose in WC did not appear. It is considered that the cellulose component in WC was decomposed together with PVC at a lower temperature. After the Co-HTC of $\mathrm{PVC}$ and $\mathrm{WC}$ at $240^{\circ} \mathrm{C}$, the peak at $340^{\circ} \mathrm{C}$ was observed due to the progress of PVC dechlorination.

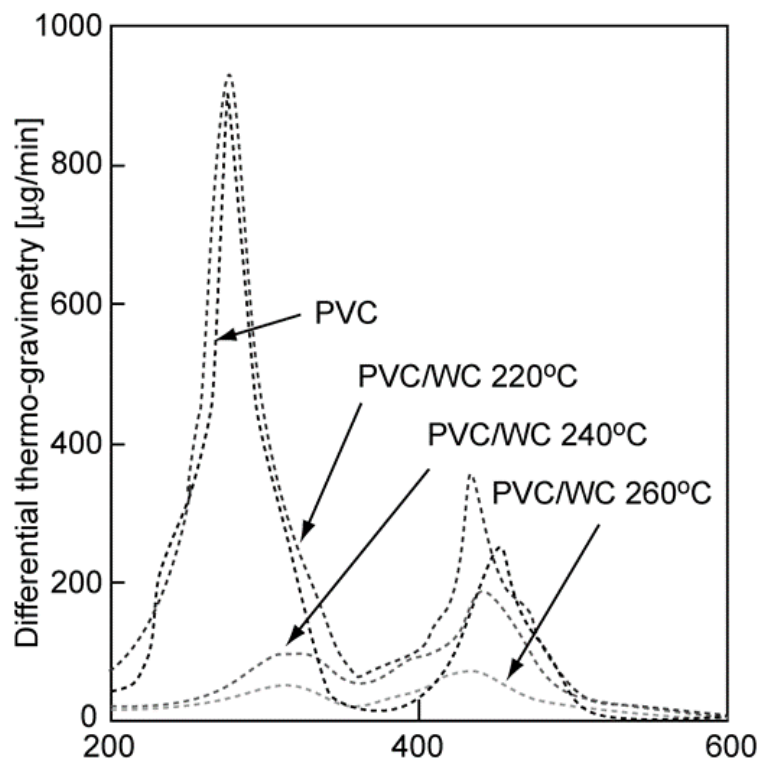

Figure 7. DTG curves obtained from the feedstock PVC and the hydrochar after Co-HTC of PVC and WC

\section{Conclusion}

Co-hydrothermal carbonization (Co-HTC) process was used to treat the WC and PVC wastes in order to produce hydrochar with dechlorination of PVC. Although the decomposition and the dechlorination of the feedstock were promoted at high temperature, the hydrochar yield became low in any conditions. Percentage decomposition in air slightly lower than in $\mathrm{N}_{2}$. This means that the oxygen-containing groups are formed on the surface of WC under the air atmosphere. The dechlorination yield for the recovered PVC after the Co-HTC was increased slightly with increasing temperature from $30 \%$ at $220^{\circ} \mathrm{C}$ to $40 \%$ at $260^{\circ} \mathrm{C}$ in $\mathrm{N}_{2}$. Judging from this result and the DTG of hydrochar, it indicates that dechlorination is progressing at a low temperature stage. Further research for the improvement of the synergic effect on dechlorination during Co-HTC at low temperatures is needed.

\section{References}

[1] Kou S C, Lee G, Poon C S and Lai W L 2009 Waste Manage. 29621

[2] López A. de Marco I, Caballero B M, Laresgoiti M F and Adrados A 2011 Fuel Process. Technol. 92253

[3] Melendi S, Diez M A, Alvarez R and Barriocanal C 2011 Fuel Process. Technol. 92471

[4] Asanuma M, Ariyama T and Iemoto M $2000 \mathrm{~J}$. Jpn. Inst. Energy 79210.

[5] Krylova A Y and Zaitchenko V M 2018 Solid Fuel Chem. 5291

[6] Poerschmann J, Weiner B, Woszidlo S, Koehler $\mathrm{R}$ and Kopinke F D 2015 Chemosphere 119682

[7] Shen Y, Shili Y, Ge S, Chen X, Ge X and Chen M 2017 Energy 118312

[8] Yao Z and Ma X 2018 Bioresource Technol. 247 302

[9] Huang N, Zhao P, Ghosh S and Fedyukhin A 2019 Appl. Energ. 240882

[10] Hiertberg T and Sorvik E M 1983, Polymer 24 673

[11] Yang H, Yan R, Chen H, Lee D H and Zheng C. 2007, Fuel, 861781.

[12] de Silva, C M S, Miguel, C, Vital, B R, Carneiro A C O, Costa, E V S, de Magalhaes, M A and Trugilho P F 2017 Ind, Crop. Products, 109598.

[13] Yu J, Sun L, Ma C, Giao Y and Yao H 2016, Waste Manage. 48300.

* Corresponding author: kusakabe@nano.sojo-u.ac.jp 